\title{
Dynamic Modeling and Analysis of a Novel 6-DOF Robotic Crusher Based on Movement Characteristics
}

\author{
Guoguang Li, Boqiang Shi $\mathbb{D}_{\text {, }}$, and Ruiyue Liu \\ School of Mechanical Engineering, University of Science and Technology Beijing, Beijing 100083, China \\ Correspondence should be addressed to Boqiang Shi; shiboqiang@ustb.edu.cn
}

Received 27 April 2019; Accepted 15 July 2019; Published 24 July 2019

Academic Editor: Ning Sun

Copyright (C) 2019 Guoguang Li et al. This is an open access article distributed under the Creative Commons Attribution License, which permits unrestricted use, distribution, and reproduction in any medium, provided the original work is properly cited.

\begin{abstract}
This paper proposes a novel 6-DOF robotic crusher that combines the performance characteristics of the cone crusher and parallel robot, such as interparticle breakage and high flexibility. Kinematics and dynamics are derived from the no-load and crushing parts in order to clearly describe the whole crushing process. For the no-load case, the kinematic and dynamic equations are established by using analytical geometry and Lagrange equation. Analytical geometry is mainly used to solve the inverse kinematics and then establish the velocity relationship between generalized coordinates and actuators. Lagrange equation which takes into account the weight of the mantle and actuators is used to solve driving forces of actuators. For the crushing case, crushing pressure is related to the compression ratio and particle size distribution, but the selection and breakage functions should be established first. Because the trajectory model of the mantle is difficult to be established by using analytical method, it can be obtained by an eccentric simulation. The results of input velocities and driving forces of actuators are distinctive due to the eccentric angle and selection of the initial position. Finally, the proposed approach is verified by a numerical example and then the energy consumption is calculated.
\end{abstract}

\section{Introduction}

Crushers are commonly used in the mining, construction, and recycling industries to crush a variety of raw materials [1]. Many different types of crushers have been developed over the years, which play a vital role in reducing the particle size of granular solids [2]. As one of the typical crushers, cone crusher is an indispensable piece of equipment [3]. It is typically used in secondary and tertiary crushing stages in minerals processing plants $[4,5]$. The mantle and concave are the two main crushing parts. The main shaft of the mantle is suspended on a spherical radial bearing at the top and in an eccentric at the bottom [6]. The crushing action of the mantle around the pivot point is an oscillating motion which can be described with a cyclic function of the eccentric angle. Previous research of scholars has made the performance experience a significant improvement, but cone crusher is inevitably accompanied by high power consumption and low flexibility due to its own structural characteristics. Meanwhile, the parallel robot has received a great concern from many researchers. Compared with serial robot, the parallel robot is a closed-loop mechanism presenting very good potential in terms of high stiffness, large payload, and high speed capability [7-10]. It has been widely used in many fields, such as medical equipment, entertainment, and factory automation [11]. The forward kinematic solution is more complicated than inverse kinematic solution because of the coupling among actuators. The mantle motion of cone crusher is usually set in advance and then the motors are adjusted, which is similar to the inverse kinematic solution. Contemporary crushers are developing towards intelligence. This paper proposes a novel 6-DOF robotic crusher which has their respective advantages through combining the performance characteristics of the cone crusher and parallel robot.

A novel 6-DOF robotic crusher has achieved both interparticle breakage of a cone crusher and high flexibility of a parallel robot. In order to systematically describe the performance characteristics of the whole crushing process, modeling and analysis would be performed from the no-load and crushing parts. Kinematics and dynamics are essential research issues in evaluating the performance. For the noload case, the inverse kinematic solution which describes the velocity relationship between generalized coordinates and actuators is established. It plays a vital role in the design and 


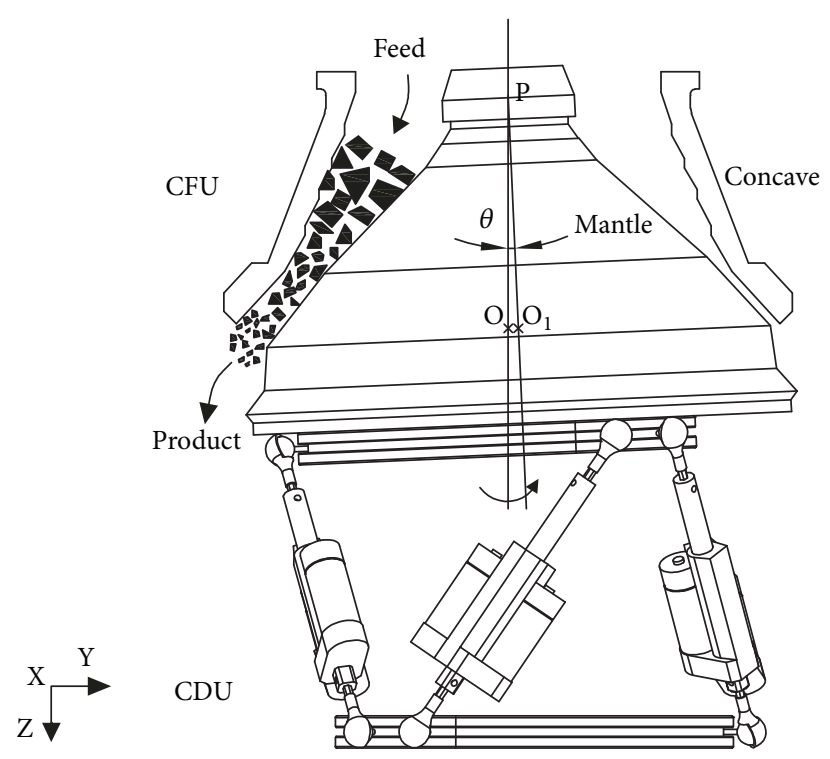

FIGURE 1: Cross section of a 6-DOF robotic crusher.

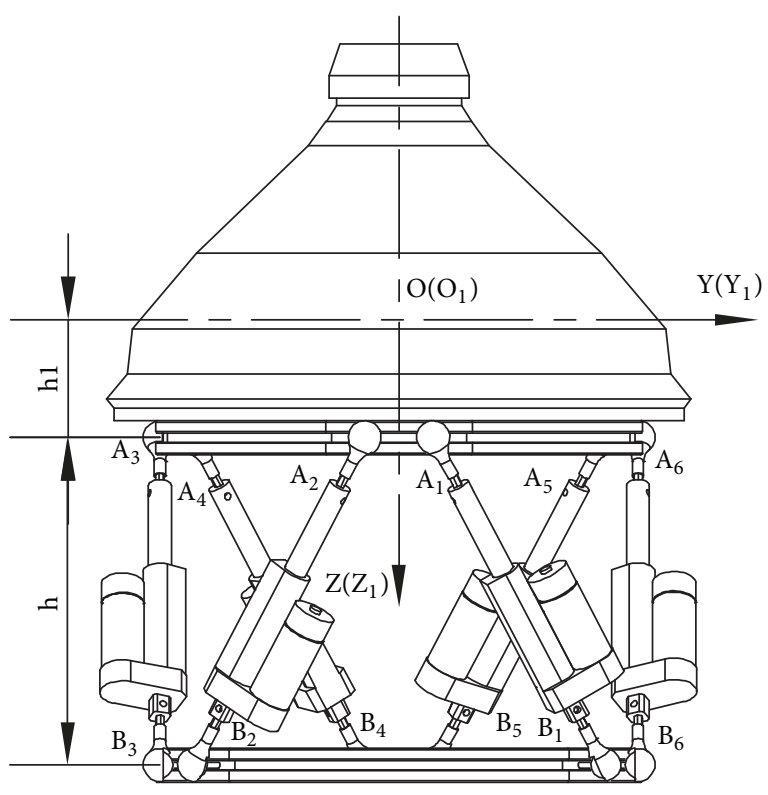

FIGURE 2: The model of CDU. component selection [12]. The dynamics of a 6-DOF robotic crusher are complicated by the existence of multiple closedloop chains, which have several effects caused by inertia, centripetal, and gravity forces [13]. Dynamic modeling can be used for computer simulation without the need of a real system to test various specified tasks, and it plays an important part in system control $[14,15]$. Dynamic equations accounting for the parallel configuration of a 6-DOF robotic crusher can be derived in the task-space through the modeling approach of Lagrange equation which provides a well analytical and orderly structure. For the crushing case, the crushing process can be described by a number of crushing zones. The output from the previous crushing zone is the input for the next crushing zone. Crushing pressure is generated on the surfaces of the mantle and concave, and it is related to the compression ratio and particle size distribution.

The trajectory model of the mantle is an essential element for establishing the kinematic and dynamic equations. But it is very difficult to be established by using analytical method. Taking into account the motion characteristics of cone crusher, a small-scale cone crusher is created and the model is obtained by an eccentric simulation. Then, the mathematical calculation tools, MATLAB and Maple, can be employed to solve the input velocities and driving forces of the actuators.

\section{Mathematical Foundation}

2.1. Principle of a 6-DOF Robotic Crusher. 3D geometric model of a novel 6-DOF robotic crusher is shown in Figure 1, which consists of a fixed unit (CFU) and a drive unit (CDU). The CDU has six actuators. Each actuator is made up of a cylinder and a piston which are connected together by a prismatic joint. The upper and lower ends of each actuator are both spherical joint. A coordinate frame $\mathrm{O}(\mathrm{X}, \mathrm{Y}, \mathrm{Z})$ is attached to the fixed base and the other coordinate frame $\mathrm{O}_{1}\left(\mathrm{X}_{1}, \mathrm{Y}_{1}, \mathrm{Z}_{1}\right)$ is attached to the mantle.

Particles are squeezed and crushed between the mantle and concave. The transition of the closed side setting (CSS) and open side setting (OSS) is achieved by the extension and contraction of six actuators. The motion of the mantle can be described by a cyclic function of the eccentric angle $\theta$ which represents the angle between the eccentric axis and vertical axis. The final crushed material is excluded from the OSS due to gravity.

A generalized coordinate vector which describes the position and orientation of a 6 -DOF robotic crusher is defined as $\mathbf{q}=[x, y, z, \alpha, \beta, \gamma]^{\mathrm{T}}$. In Figure 2, the matrix $\mathbf{q}_{\mathrm{p}}=[x, y, z]^{\mathrm{T}}$ denotes the translation vector of the mantle frame $\left\{\mathrm{O}_{1}, \mathrm{X}_{1}, \mathrm{Y}_{1}, \mathrm{Z}_{1}\right\}$ with respect to the reference frame $\{\mathrm{O}, \mathrm{X}, \mathrm{Y}, \mathrm{Z}\} . \mathbf{q}_{\mathrm{e}}=[\alpha, \beta, \gamma]^{\mathrm{T}}$ defines an Euler angles system representing orientation of the mantle frame $\left\{\mathrm{O}_{1}, \mathrm{X}_{1}, \mathrm{Y}_{1}, \mathrm{Z}_{1}\right\}$ in regard to the reference frame $\{\mathrm{O}, \mathrm{X}, \mathrm{Y}, \mathrm{Z}\}[16]$.

2.2. Kinematic Constraint Equations. Inverse kinematic is to solve the lengths and velocities of six actuators through the trajectory model of the mantle. The rotation matrix of frame $\left\{\mathrm{O}_{1}, \mathrm{X}_{1}, \mathrm{Y}_{1}, \mathrm{Z}_{1}\right\}$ relative to the reference frame $\{\mathrm{O}, \mathrm{X}, \mathrm{Y}, \mathrm{Z}\}$ is given by [14]

$$
\mathbf{T}=\mathbf{T}_{\mathrm{Z}} \mathbf{T}_{\mathrm{Y}} \mathbf{T}_{\mathrm{X}}
$$

where

$$
\mathbf{T}_{\mathrm{X}}=\left[\begin{array}{ccc}
1 & 0 & 0 \\
0 & \cos \alpha & -\sin \alpha \\
0 & \sin \alpha & \cos \alpha
\end{array}\right],
$$




$$
\begin{aligned}
& \mathbf{T}_{\mathrm{Y}}=\left[\begin{array}{ccc}
\cos \beta & 0 & \sin \beta \\
0 & 1 & 0 \\
-\sin \beta & 0 & \cos \beta
\end{array}\right], \\
& \mathbf{T}_{\mathrm{Z}}=\left[\begin{array}{ccc}
\cos \gamma & -\sin \gamma & 0 \\
\sin \gamma & \cos \gamma & 0 \\
0 & 0 & 1
\end{array}\right]
\end{aligned}
$$

From the geometric model of the 6-DOF robotic crusher, vector $\mathbf{L}_{\mathbf{i}}$ can be expressed as [16-18]

$$
\mathbf{L}_{i}=\mathbf{p}+\mathbf{T a}_{i}-\mathbf{b}_{i}
$$

where $\mathbf{L}_{\mathrm{i}}(\mathrm{i}=1,2, \ldots, 6)$ denotes the length vector of each actuator, which is $B_{i}$ to $A_{i}$ in O-XYZ. $\mathbf{a}_{\mathrm{i}}(\mathrm{i}=1,2, \ldots, 6)$ represents the coordinates of $A_{i}(\mathrm{i}=1,2, \ldots, 6)$ in $\mathrm{O}_{1}-\mathrm{X}_{1} \mathrm{Y}_{1} \mathrm{Z}_{1} \cdot \mathbf{b}_{\mathrm{i}}(\mathrm{i}=1,2, \ldots, 6)$ denotes the coordinates of $B_{i}(\mathrm{i}=1,2, \ldots, 6)$ in $\mathrm{O}-\mathrm{XYZ}$.

Differentiate $T_{X}, T_{Y}$, and $T_{Z}$ with respect to time:

$$
\begin{aligned}
& \dot{\mathbf{T}}_{\mathrm{X}}=\mathbf{S}_{\mathrm{i}} \mathbf{T}_{\mathrm{X}} \dot{\alpha}, \\
& \dot{\mathbf{T}}_{\mathrm{Y}}=\mathbf{S}_{\mathrm{j}} \mathbf{T}_{\mathrm{Y}} \dot{\beta}, \\
& \dot{\mathbf{T}}_{\mathrm{Z}}=\mathbf{S}_{\mathrm{k}} \mathbf{T}_{\mathrm{Z}} \dot{\gamma}
\end{aligned}
$$

where

$$
\begin{aligned}
& \mathbf{S}_{\mathrm{i}}=\left[\begin{array}{ccc}
0 & 0 & 0 \\
0 & 0 & -1 \\
0 & 1 & 0
\end{array}\right], \\
& \mathbf{S}_{\mathrm{j}}=\left[\begin{array}{ccc}
0 & 0 & 1 \\
0 & 0 & 0 \\
-1 & 0 & 0
\end{array}\right], \\
& \mathbf{S}_{\mathrm{k}}=\left[\begin{array}{ccc}
0 & -1 & 0 \\
1 & 0 & 0 \\
0 & 0 & 0
\end{array}\right],
\end{aligned}
$$

The velocity vector of six actuators and the corresponding upper points is given by

$$
\mathbf{V}=\mathbf{Q} \cdot \mathbf{V}_{\mathrm{a}}
$$

where

$$
\begin{aligned}
\mathbf{V} & =\left[\begin{array}{llllll}
\dot{L}_{1} & \dot{L}_{2} & \dot{L}_{3} & \dot{L}_{4} & \dot{L}_{5} & \dot{L}_{6}
\end{array}\right]^{T}, \\
\mathbf{V}_{\mathrm{a}} & =\left[\begin{array}{llllll}
\dot{\mathbf{L}}_{1} & \dot{\mathbf{L}}_{2} & \dot{\mathbf{L}}_{3} & \dot{\mathbf{L}}_{4} & \dot{\mathbf{L}}_{5} & \dot{\mathbf{L}}_{6}
\end{array}\right]^{\mathrm{T}}
\end{aligned}
$$

The derivations of (4) and (6) are in the appendix.

Differentiate (3) with respect to time:

$$
\begin{aligned}
\dot{\mathbf{L}}_{i}= & \dot{\mathbf{p}} \\
& +\left(\dot{\gamma} \mathbf{S}_{\mathrm{k}} \mathbf{T}_{\mathrm{Z}} \mathbf{T}_{\mathrm{Y}} \mathbf{T}_{\mathrm{X}}+\mathbf{T}_{\mathrm{Z}} \dot{\beta} \mathbf{S}_{\mathrm{j}} \mathbf{T}_{\mathrm{Y}} \mathbf{T}_{\mathrm{X}}+\mathbf{T}_{\mathrm{Z}} \mathbf{T}_{\mathrm{Y}} \dot{\alpha} \mathbf{S}_{\mathrm{i}} \mathbf{T}_{\mathrm{X}}\right) \mathbf{a}_{i}
\end{aligned}
$$

Equation (8) can be rewritten as

$$
\dot{\mathbf{L}}_{i}=\mathbf{H}_{\mathrm{i}} \cdot \dot{\mathbf{q}}
$$

where

$$
\mathbf{H}_{\mathrm{i}}=\left[\begin{array}{llllll}
\mathbf{I}_{3 \times 3} & \mathbf{T}_{\mathrm{Z}} \mathbf{T}_{\mathrm{Y}} \mathbf{S}_{\mathrm{i}} \mathbf{T}_{\mathrm{X}} \mathbf{a}_{i} & \mathbf{T}_{\mathrm{Z}} \mathbf{S}_{\mathrm{j}} \mathbf{T}_{\mathrm{Y}} \mathbf{T}_{\mathrm{X}} \mathbf{a}_{i} & \mathbf{S}_{\mathrm{k}} \mathbf{T}_{\mathrm{Z}} \mathbf{T}_{\mathrm{Y}} \mathbf{T}_{\mathrm{X}} \mathbf{a}_{i}
\end{array}\right]
$$

Using (8) and (9) yields

$$
\mathbf{V}_{\mathrm{a}}=\mathbf{H} \cdot \dot{\mathbf{q}}
$$

where

H

$$
=\left[\begin{array}{cccc}
\mathbf{I}_{3 \times 3} & \mathbf{T}_{\mathrm{Z}} \mathbf{T}_{\mathrm{Y}} \mathbf{S}_{\mathrm{i}} \mathbf{T}_{\mathrm{X}} \mathbf{a}_{1} & \mathbf{T}_{\mathrm{Z}} \mathbf{S}_{\mathrm{j}} \mathbf{T}_{\mathrm{Y}} \mathbf{T}_{\mathrm{X}} \mathbf{a}_{1} & \mathbf{S}_{\mathrm{k}} \mathbf{T}_{\mathrm{Z}} \mathbf{T}_{\mathrm{Y}} \mathbf{T}_{\mathrm{X}} \mathbf{a}_{1} \\
\mathbf{I}_{3 \times 3} & \mathbf{T}_{\mathrm{Z}} \mathbf{T}_{\mathrm{Y}} \mathbf{S}_{\mathrm{i}} \mathbf{T}_{\mathrm{X}} \mathbf{a}_{2} & \mathbf{T}_{\mathrm{Z}} \mathbf{S}_{\mathrm{j}} \mathbf{T}_{\mathrm{Y}} \mathbf{T}_{\mathrm{X}} \mathbf{a}_{2} & \mathbf{S}_{\mathrm{k}} \mathbf{T}_{\mathrm{Z}} \mathbf{T}_{\mathrm{Y}} \mathbf{T}_{\mathrm{X}} \mathbf{a}_{2} \\
\mathbf{I}_{3 \times 3} & \mathbf{T}_{\mathrm{Z}} \mathbf{T}_{\mathrm{Y}} \mathbf{S}_{\mathrm{i}} \mathbf{T}_{\mathrm{X}} \mathbf{a}_{3} & \mathbf{T}_{\mathrm{Z}} \mathbf{S}_{\mathrm{j}} \mathbf{T}_{\mathrm{Y}} \mathbf{T}_{\mathrm{X}} \mathbf{a}_{3} & \mathbf{S}_{\mathrm{k}} \mathbf{T}_{\mathrm{Z}} \mathbf{T}_{\mathrm{Y}} \mathbf{T}_{\mathrm{X}} \mathbf{a}_{3} \\
\mathbf{I}_{3 \times 3} & \mathbf{T}_{\mathrm{Z}} \mathbf{T}_{\mathrm{Y}} \mathbf{S}_{\mathrm{i}} \mathbf{T}_{\mathrm{X}} \mathbf{a}_{4} & \mathbf{T}_{\mathrm{Z}} \mathbf{S}_{\mathrm{j}} \mathbf{T}_{\mathrm{Y}} \mathbf{T}_{\mathrm{X}} \mathbf{a}_{4} & \mathbf{S}_{\mathrm{k}} \mathbf{T}_{\mathrm{Z}} \mathbf{T}_{\mathrm{Y}} \mathbf{T}_{\mathrm{X}} \mathbf{a}_{4} \\
\mathbf{I}_{3 \times 3} & \mathbf{T}_{\mathrm{Z}} \mathbf{T}_{\mathrm{Y}} \mathbf{S}_{\mathrm{i}} \mathbf{T}_{\mathrm{X}} \mathbf{a}_{5} & \mathbf{T}_{\mathrm{Z}} \mathbf{S}_{\mathrm{j}} \mathbf{T}_{\mathrm{Y}} \mathbf{T}_{\mathrm{X}} \mathbf{a}_{5} & \mathbf{S}_{\mathrm{k}} \mathbf{T}_{\mathrm{Z}} \mathbf{T}_{\mathrm{Y}} \mathbf{T}_{\mathrm{X}} \mathbf{a}_{5} \\
\mathbf{I}_{3 \times 3} & \mathbf{T}_{\mathrm{Z}} \mathbf{T}_{\mathrm{Y}} \mathbf{S}_{\mathrm{i}} \mathbf{T}_{\mathrm{X}} \mathbf{a}_{6} & \mathbf{T}_{\mathrm{Z}} \mathbf{S}_{\mathrm{j}} \mathbf{T}_{\mathrm{Y}} \mathbf{T}_{\mathrm{X}} \mathbf{a}_{6} & \mathbf{S}_{\mathrm{k}} \mathbf{T}_{\mathrm{Z}} \mathbf{T}_{\mathrm{Y}} \mathbf{T}_{\mathrm{X}} \mathbf{a}_{6}
\end{array}\right]
$$

Substituting (11) into (6) yields

$$
\mathbf{V}=\mathbf{J}_{\mathrm{q}} \cdot \dot{\mathbf{q}}
$$

where $\mathbf{J}_{\mathbf{q}}$ presents a Jacobian matrix, which can be described as

$$
\mathbf{J}_{\mathrm{q}}=\mathbf{Q} \cdot \mathbf{H}
$$

\section{Dynamic Modeling}

Lagrange equation is used to derive the driving forces of six actuators for the 6-DOF robotic crusher, which can be written as [19]

$$
\frac{\mathrm{d}}{\mathrm{d} t}\left(\frac{\partial L}{\partial \dot{q}_{i}}\right)-\frac{\partial L}{\partial q_{i}}=\tau_{i}
$$

where $L$ is the kinetic energy $E_{k}$ minus the potential energy $E_{p} \cdot q_{i}$ denotes the generalized coordinate, and $\tau_{i}$ is the generalized force.

According the principle of virtual work, the generalized force which is projected along the variation of the generalized coordinates can be derived as follows $[14,20]$ :

$$
\partial W=\mathbf{F}^{\mathrm{T}} \delta l-\boldsymbol{\tau}^{\mathrm{T}} \delta \mathbf{q}=0
$$

where $\mathbf{F}$ denotes the matrix of six driving forces. Equation (13) has been employed, and then (16) can be rewritten as

$$
\boldsymbol{\tau}=\mathbf{J}_{\mathrm{q}}^{\mathrm{T}}\left(f_{1}, f_{2}, f_{3}, f_{4}, f_{5}, f_{6}\right)^{\mathrm{T}}
$$

3.1. Dynamic Model Components. The kinetic energy of the mantle includes its translational kinetic energy and rotational kinetic energy with respect to its center of mass, which can be written as 


$$
E_{m k}=\frac{1}{2} \dot{\mathbf{q}}_{\mathrm{p}}^{\mathrm{T}} M_{u} \dot{\mathbf{q}}_{\mathrm{p}}+\frac{1}{2} \boldsymbol{\omega}_{\mathrm{O} 1}{ }^{\mathrm{T}} \mathbf{I}_{\mathrm{O} 1} \boldsymbol{\omega}_{\mathrm{O} 1}
$$

where $M_{u}$ denotes the mass of the mantle, $\boldsymbol{\omega}_{\mathrm{O} 1}$ is the angular velocity vector of the mantle with respect to the mantle frame, and $\mathbf{I}_{\mathrm{O} 1}$ is the rotational inertia matrix in regard to mass center of the mantle.

After simplifying deriving, the relation between the angular velocity and the derivatives of Euler angles with respect to time can be given by

$$
\boldsymbol{\omega}_{\mathrm{O} 1}=\left[\begin{array}{ccc}
\cos \gamma \cos \beta & -\sin \gamma & 0 \\
\sin \gamma \cos \beta & \cos \gamma & 0 \\
-\sin \beta & 0 & 1
\end{array}\right] \cdot\left(\begin{array}{c}
\dot{\alpha} \\
\dot{\beta} \\
\dot{\gamma}
\end{array}\right)
$$

Substituting (19) into (18) yields

$$
E_{m k}=\frac{1}{2} \dot{\mathbf{q}}^{\mathrm{T}} \mathbf{M}_{\mathrm{p}} \dot{\mathbf{q}}
$$

where

$$
\mathbf{M}_{\mathrm{p}}=\left[\begin{array}{cccccc}
M_{u} & 0 & 0 & 0 & 0 & 0 \\
0 & M_{u} & 0 & 0 & 0 & 0 \\
0 & 0 & M_{u} & 0 & 0 & 0 \\
0 & 0 & 0 & I_{X} & 0 & -I_{X} \sin \beta \\
0 & 0 & 0 & 0 & I_{Y} \cos ^{2} \alpha+I_{Z} \sin ^{2} \alpha & \left(I_{Y}-I_{Z}\right) \sin \alpha \cos \alpha \cos \beta \\
0 & 0 & 0 & -I_{X} \sin \beta & \left(I_{Y}-I_{Z}\right) \sin \alpha \cos \alpha \cos \beta I_{X} \sin ^{2} \beta+I_{Y} \sin ^{2} \alpha \cos ^{2} \beta+I_{Z} \cos ^{2} \alpha \cos ^{2} \beta
\end{array}\right]
$$

The potential energy of the mantle relative to the horizontal plane passing by the reference frame $\{\mathrm{O}, \mathrm{X}, \mathrm{Y}, \mathrm{Z}\}$ is

$$
E_{m p}=-M_{u} g Z
$$

In Figure $3, l_{i}$ denotes the length of the $i$ th actuator; $g_{i}$ represents the length between the lower spherical joint and the center of mass. $S_{1}$ is the length between the lower spherical joint and the center of mass of a cylinder. $S_{2}$ is the length between the upper spherical joint and the center of mass of a piston [19]. Then, the length $g_{i}$ can be denoted as

$$
g_{i}=l_{c}+\frac{m_{2}}{m_{1}+m_{2}} l_{i}
$$

where

$$
l_{c}=\frac{m_{1} s_{1}-m_{2} s_{2}}{m_{1}+m_{2}}
$$

The kinetic energy of six actuators can be driven by

$$
E_{a k}=\frac{1}{2}\left(m_{1}+m_{2}\right) \mathbf{V}_{\mathrm{g}}^{\mathrm{T}} \mathbf{V}_{g}
$$

where $\mathbf{V}_{\mathrm{g}}$ denotes the matrix of velocity vectors for the center of mass and can be given by

$$
\mathbf{V}_{\mathrm{g}}=\left[\mathbf{V}_{\mathrm{g} 1}^{\mathrm{T}}, \mathbf{V}_{\mathrm{g} 2}^{\mathrm{T}}, \mathbf{V}_{\mathrm{g} 3}^{\mathrm{T}}, \mathbf{V}_{\mathrm{g} 4}^{\mathrm{T}}, \mathbf{V}_{\mathrm{g} 5}^{\mathrm{T}}, \mathbf{V}_{\mathrm{g} 6}^{\mathrm{T}}\right]^{\mathrm{T}}
$$

The derivation of (26) is in the appendix.

Substituting (26) into (25), then (25) can be denoted as

$$
E_{a k}=\frac{1}{2}\left(m_{1}+m_{2}\right) \dot{\mathbf{q}}^{\mathrm{T}} \mathbf{H}^{\mathrm{T}} \mathbf{T}_{\mathrm{m}} \mathbf{H} \dot{\mathbf{q}}
$$

where

$$
\begin{aligned}
& \mathbf{T}_{\mathrm{m}}=\operatorname{diag}\left[\left(\frac{l_{c}}{l_{1}}+\frac{m_{2}}{m_{1}+m_{2}}\right)^{2},\left(\frac{l_{c}}{l_{1}}+\frac{m_{2}}{m_{1}+m_{2}}\right)^{2},\right. \\
& \left(\frac{l_{c}}{l_{1}}+\frac{m_{2}}{m_{1}+m_{2}}\right)^{2},\left(\frac{l_{c}}{l_{2}}+\frac{m_{2}}{m_{1}+m_{2}}\right)^{2}, \\
& \left(\frac{l_{c}}{l_{2}}+\frac{m_{2}}{m_{1}+m_{2}}\right)^{2},\left(\frac{l_{c}}{l_{2}}+\frac{m_{2}}{m_{1}+m_{2}}\right)^{2}, \\
& \left(\frac{l_{c}}{l_{3}}+\frac{m_{2}}{m_{1}+m_{2}}\right)^{2},\left(\frac{l_{c}}{l_{3}}+\frac{m_{2}}{m_{1}+m_{2}}\right)^{2}, \\
& \left(\frac{l_{c}}{l_{3}}+\frac{m_{2}}{m_{1}+m_{2}}\right)^{2},\left(\frac{l_{c}}{l_{4}}+\frac{m_{2}}{m_{1}+m_{2}}\right)^{2}, \\
& \left(\frac{l_{c}}{l_{4}}+\frac{m_{2}}{m_{1}+m_{2}}\right)^{2},\left(\frac{l_{c}}{l_{4}}+\frac{m_{2}}{m_{1}+m_{2}}\right)^{2}, \\
& \left(\frac{l_{c}}{l_{5}}+\frac{m_{2}}{m_{1}+m_{2}}\right)^{2},\left(\frac{l_{c}}{l_{5}}+\frac{m_{2}}{m_{1}+m_{2}}\right)^{2}, \\
& \left.\left(\frac{l_{c}}{l_{5}}+\frac{m_{2}}{m_{1}+m_{2}}\right)^{2},\left(\frac{l_{c}}{l_{6}}+\frac{m_{2}}{m_{1}+m_{2}}\right)^{2},\left(\frac{l_{c}}{l_{6}}+\frac{m_{2}}{m_{1}+m_{2}}\right)^{2}\right]
\end{aligned}
$$

The unit vectors along the axes OX, OY, and $\mathrm{OZ}$ are defined as

$$
\begin{aligned}
& \mathbf{X} \_1=[1,0,0], \\
& Y_{-1}=[0,1,0], \\
& \mathbf{Z}_{-1}=[0,1,0]
\end{aligned}
$$




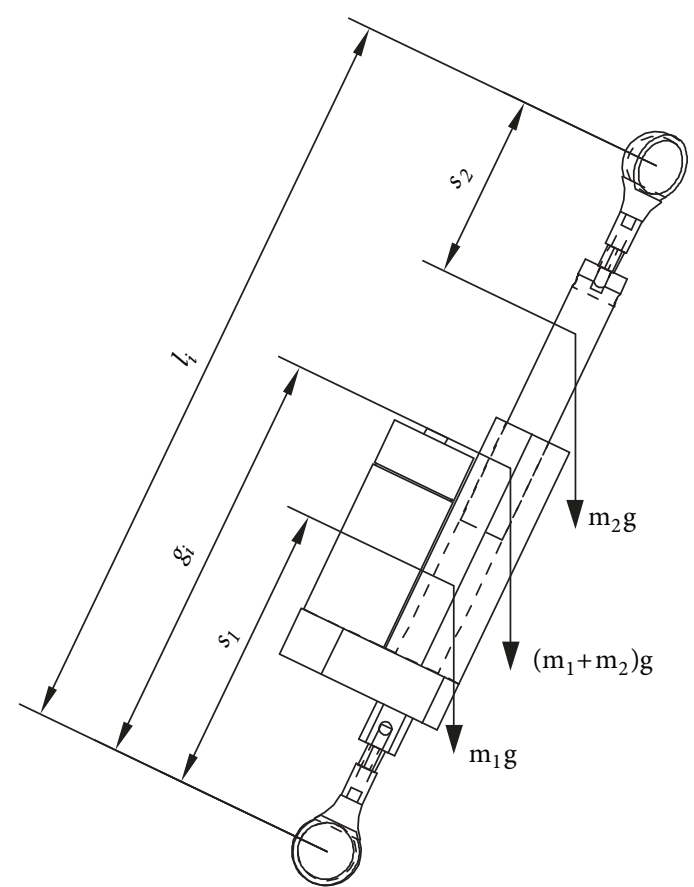

FIGURE 3: Free body diagram of an actuator.

The potential energy of six actuators relative to the horizontal plane passing by the reference frame $\{\mathrm{O}, \mathrm{X}, \mathrm{Y}, \mathrm{Z}\}$ is

$$
E_{a p}=-\left(m_{1}+m_{2}\right) g \cdot \sum_{i=1}^{6}\left[\left(h+h_{1}\right)-g_{i} \cdot\left(-Z_{-} 1\right)\right]
$$

Equation (23) has been employed, and then (30) can be rewritten as

$$
E_{a p}=-\left(m_{1}+m_{2}\right) g\left[6\left(h+h_{1}\right)+\mathbf{T}_{-} \mathrm{h}_{\mathrm{gi}} \cdot \mathbf{T}_{-} \mathrm{l}_{\mathrm{iz}}\right]
$$

where

$$
\begin{aligned}
& \mathbf{T}_{-} \mathrm{h}_{\mathrm{gi}}=\left[\frac{l_{c}}{l_{1}}+\frac{m_{2}}{m_{1}+m_{2}}, \frac{l_{c}}{l_{2}}+\frac{m_{2}}{m_{1}+m_{2}}, \cdots, \frac{l_{c}}{l_{6}}\right. \\
& \left.\quad+\frac{m_{2}}{m_{1}+m_{2}}\right] \\
& \mathbf{T}_{-} \mathrm{l}_{\mathrm{iz}}=\left[\begin{array}{llllll}
l_{1 z} & l_{2 z} & l_{3 z} & l_{4 z} & l_{5 z} & l_{6 z}
\end{array}\right]^{\mathrm{T}} \\
& l_{i z}=\mathbf{L}_{i} \cdot \mathbf{Z}_{-} 1
\end{aligned}
$$

3.2. Dynamic Equations. Using (20) and (27), the kinetic energy of the 6-DOF robotic crusher can be given by

$$
E_{k}=\frac{1}{2} \dot{\mathbf{q}}^{\mathrm{T}} \mathbf{M}_{\mathrm{ek}} \dot{\mathbf{q}}
$$

where

$$
\mathbf{M}_{\mathrm{ek}}=\left(m_{1}+m_{2}\right) \mathbf{H}^{\mathrm{T}} \mathbf{T}_{\mathrm{m}} \mathbf{H}+\mathbf{M}_{\mathrm{p}}
$$

The derivation of (33) is in the appendix.
Using (22) and (31), the potential energy of the 6-DOF robotic crusher can be obtained as follows:

$$
\begin{aligned}
E_{p}= & -M_{u} g \\
& -\left(m_{1}+m_{2}\right) g\left[6\left(h+h_{1}\right)+\mathbf{T}_{-} \mathrm{h}_{\mathrm{gi}} \cdot \mathbf{T}_{-} \mathrm{l}_{\mathrm{iz}}\right]
\end{aligned}
$$

Considering (15) and (33), the equations can be derived as

$$
\begin{aligned}
\frac{\mathrm{d}}{\mathrm{d} t}\left(\frac{\partial L}{\partial \dot{\mathbf{q}}}\right) & =\dot{\mathbf{M}}_{\mathrm{ek}} \dot{\mathbf{q}}+\mathbf{M}_{\mathrm{ek}} \ddot{\mathbf{q}} \\
\frac{\partial E_{k}}{\partial \mathbf{q}} & =\frac{1}{2} \dot{\mathbf{q}}^{\mathrm{T}}\left(\frac{\partial \mathbf{M}_{\mathrm{ek}}}{\partial \mathbf{q}}\right) \dot{\mathbf{q}}
\end{aligned}
$$

where

$$
\begin{aligned}
& \dot{\mathbf{M}}_{\mathrm{ek}} \\
& =\left(m_{1}+m_{2}\right)\left[\frac{\mathrm{d} \mathbf{H}^{\mathrm{T}}}{\mathrm{d} t} \mathbf{T}_{\mathrm{m}} \mathbf{H}+\mathbf{H}^{\mathrm{T}} \frac{\mathrm{d} \mathbf{T}_{\mathrm{m}}}{\mathrm{d} t} \mathbf{H}+\mathbf{H}^{\mathrm{T}} \mathbf{T}_{\mathrm{m}} \frac{\mathrm{d} \mathbf{H}}{\mathrm{d} t}\right] \\
& \quad+\dot{\mathbf{M}}_{\mathrm{p}}
\end{aligned}
$$

The derivation of (36) and (37) is in the appendix.

Using (15) and (35), the following equations can be given by

$$
\begin{aligned}
& \frac{\partial E_{p}}{\partial X}=\left(m_{1}+m_{2}\right) g l_{c} \cdot \mathbf{T}_{-} \mathrm{l}_{\mathrm{ix}}{ }^{\mathrm{T}} \cdot \mathbf{T}_{-} 13 \cdot \mathbf{T}_{-} \mathrm{l}_{\mathrm{iz}} \\
& \frac{\partial E_{p}}{\partial Y}=\left(m_{1}+m_{2}\right) g l_{c} \cdot \mathbf{T}_{-} \mathrm{l}_{\mathrm{iy}}{ }^{\mathrm{T}} \cdot \mathbf{T}_{-} 13 \cdot \mathbf{T}_{-} \mathbf{l}_{\mathrm{iz}} \\
& \frac{\partial E_{p}}{\partial Z}=-M_{u} g+\left(m_{1}+m_{2}\right) \\
& \cdot g\left(l_{c} \cdot \mathbf{T}_{-} \mathrm{l}_{\mathrm{iz}}{ }^{\mathrm{T}} \cdot \mathbf{T}_{-} 13 \cdot \mathbf{T}_{-} \mathrm{l}_{\mathrm{iz}}-\mathbf{T}_{-} \mathrm{h}_{\mathrm{gi}} \cdot \mathbf{T}_{-} 1\right) \\
& \frac{\partial E_{p}}{\partial \alpha}=-\left(m_{1}+m_{2}\right) \\
& \cdot g\left[\sum_{i=1}^{6}\left(-\frac{l_{c}}{l_{i}^{2}}\right) \frac{\partial l_{i}}{\partial \alpha}+\mathbf{T}_{-} \mathrm{h}_{\mathrm{gi}} \cdot \mathbf{d} \_\mathrm{liz} \_\alpha\right] \\
& \frac{\partial E_{p}}{\partial \beta}=-\left(m_{1}+m_{2}\right) \\
& \cdot g\left[\sum_{i=1}^{6}\left(-\frac{l_{c}}{l_{i}^{2}}\right) \frac{\partial l_{i}}{\partial \beta}+\mathbf{T}_{-} \mathrm{h}_{\mathrm{gi}} \cdot \mathbf{d} \_l i z_{-} \beta\right] \\
& \frac{\partial E_{p}}{\partial \gamma}=-\left(m_{1}+m_{2}\right) \\
& \cdot g\left[\sum_{i=1}^{6}\left(-\frac{l_{c}}{l_{i}^{2}}\right) \frac{\partial l_{i}}{\partial \gamma}+\mathrm{T}_{-} \mathrm{h}_{\mathrm{gi}} \cdot \mathbf{d} \_ \text {liz_- } \gamma\right]
\end{aligned}
$$




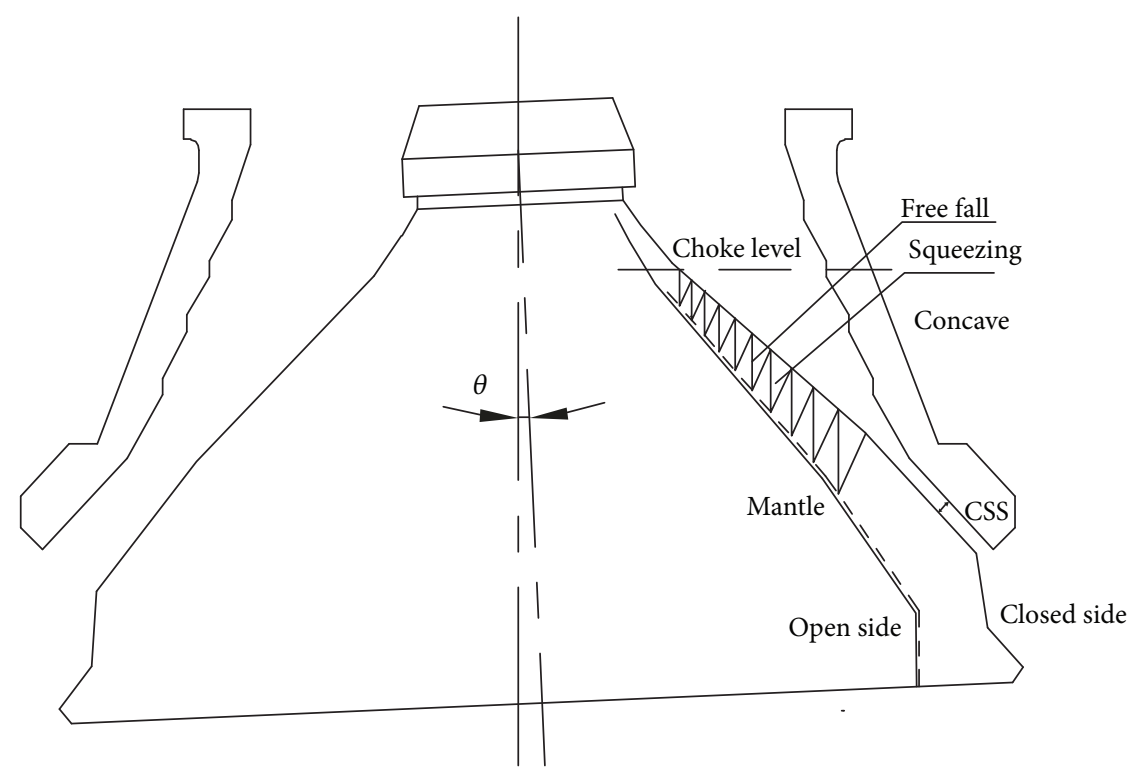

FIgURE 4: Particle trajectory.

where

$$
\begin{aligned}
& \mathbf{T}_{-} 1_{\mathrm{ix}}=\left[\begin{array}{llllll}
l_{1 x} & l_{2 x} & l_{3 x} & l_{4 x} & l_{5 x} & l_{6 x}
\end{array}\right]^{\mathrm{T}}, \\
& \mathbf{T}_{-} 1_{\text {iy }}=\left[\begin{array}{llllll}
l_{1 y} & l_{2 y} & l_{3 y} & l_{4 y} & l_{5 y} & l_{6 y}
\end{array}\right]^{\mathrm{T}} \\
& l_{i x}=\mathbf{L}_{i} \cdot \mathbf{X}_{-} 1 \text {, } \\
& l_{i y}=\mathbf{L}_{i} \cdot \mathbf{Y}_{-} 1 \text {, } \\
& \mathbf{T}_{-} 1=\left[\begin{array}{llllll}
1 & 1 & 1 & 1 & 1 & 1
\end{array}\right]^{\mathrm{T}} \\
& \mathbf{T} \_13=\operatorname{diag}\left(\begin{array}{llllll}
\frac{1}{l_{1}^{3}} & \frac{1}{l_{2}^{3}} & \frac{1}{l_{3}^{3}} & \frac{1}{l_{4}^{3}} & \frac{1}{l_{5}^{3}} & \frac{1}{l_{6}^{3}}
\end{array}\right)
\end{aligned}
$$

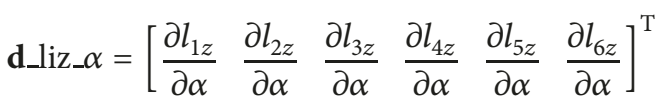

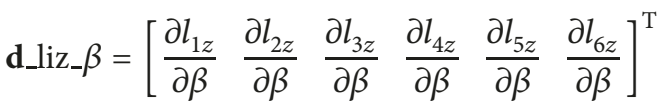

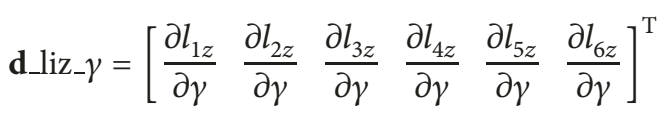

3.3. Compressive Breakage Behavior. As shown in Figure 4, the crushing process can be described by a number of different crushing zones. The feed material is crushed by the interparticle breakage and flows through each crushing zone in the crushing chamber. The material is transformed to the product by a repeated crushing process and crushed once in each crushing zone between the mantle and concave.

In Figure 5, crushing pressure $p$ is generated on the surfaces of the mantle and concave [21]. It is related to the compression ratio $\varepsilon$ and particle size distribution $\sigma$. Compression ratio represents the proportional relationship between compression length and height of crushing zone.
Particle size distribution describes the uniformity of the particle size distribution. The compressive ratio is the largest value when the material moves to the closed side. Meantime, the corresponding pressure $p$ is also the largest value of the same horizontal cross section. Crushing pressure $p$ can be represented as

$$
p=p(\varepsilon, \sigma)
$$

A process model of consecutive crushing events is presented, as shown in Figure 6. The selection function $S_{i}$ describes particles of all sizes which enter a crushing process have some probability of being broken, and the probability is constantly changing as the particle size changes. A certain proportion of particles in each size range are selected for breakage and the remainder passes through the process unbroken during the crushing events. The breakage function $B_{i}$ reflects the particle size distribution of each size range after particles are broken into smaller fragments.

The process model uses the output from the previous crushing event as input for the next crushing event. Each crushing zone corresponds to a crushing event, and the sizereduction process can be described as

$$
P=\sum_{i=1}^{n}\left[B_{i} S_{i}+\left(I-S_{i}\right)\right] F
$$

where $P$ represents the product size distribution and $F$ is the feed size distribution. The total number of crushing events is denoted as $n$.

Selection and breakage functions can be established by the compression ratio and particle size distribution through the analysis of the experimental results. Thus, $S$ and $B$ can be established as

$$
\begin{aligned}
& S=S(\varepsilon, \sigma) \\
& B=\left\{1-\left[a_{3}+a_{4} \varepsilon_{i}\right]\right\} X_{i}^{a_{1}+a_{2} \varepsilon_{i}}+\left[a_{3}+a_{4} \varepsilon_{i}\right] X_{i}
\end{aligned}
$$




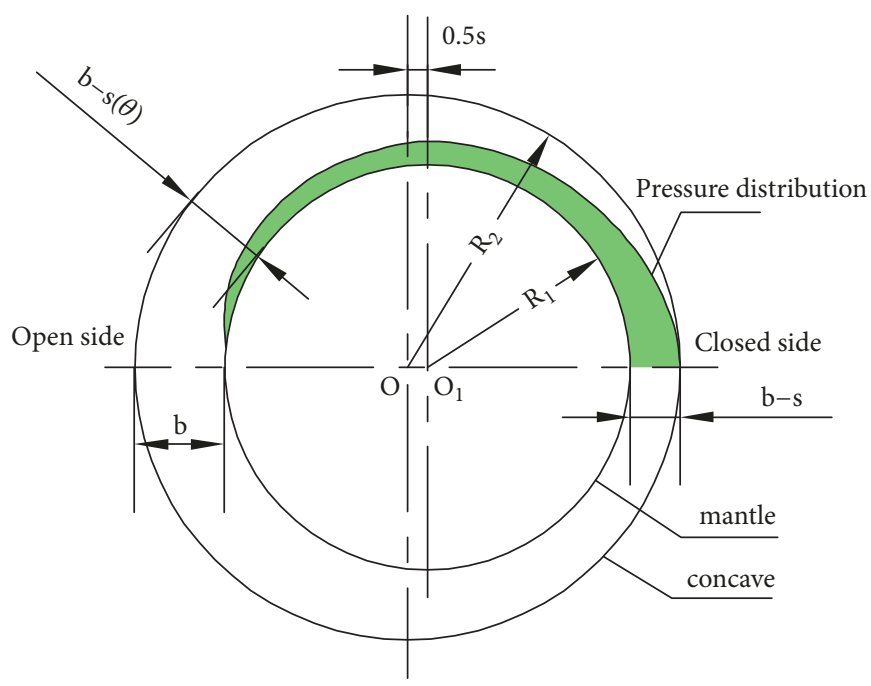

Figure 5: Pressure distribution of cross section.

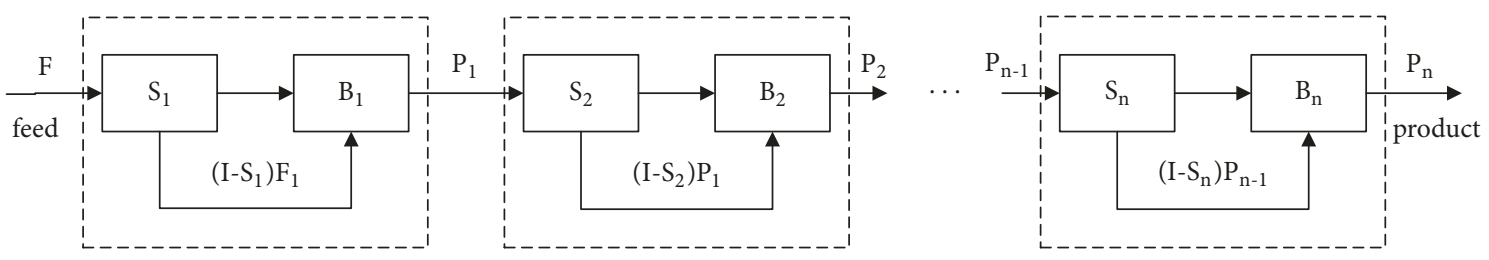

FIgURE 6: Process model of a 6-DOF robotic crusher with n consecutive crushing events.

TABLE 1: The parameters of a 6-DOF robotic crusher.

\begin{tabular}{lr}
\hline Parameters & Values \\
\hline$M_{u}$ & 182 \\
$I_{X}$ & $3.45 * 10^{6}$ \\
$I_{Y}$ & $3.45 * 10^{6}$ \\
$I_{Z}$ & $5.09 * 10^{6}$ \\
$m_{1}$ & 1.87 \\
$m_{2}$ & 0.35 \\
$S_{1}$ & 121.13 \\
$S_{2}$ & 112.48 \\
\hline
\end{tabular}

where

$$
\begin{aligned}
\sigma & =\frac{\sqrt{\sum_{i=1}^{n} c_{i}\left(\bar{d}_{i}-\bar{d}\right)^{2}}}{\sum_{i}^{n} c_{i} \bar{d}_{i}} \\
X_{i} & =\frac{l b\left(x_{i} / x_{\min }\right)}{l b\left(x_{\max } / x_{\min }\right)}
\end{aligned}
$$

where $a_{i}$ are fitted constants. $x_{\min }$ represents the minimum particle size of different crushing zones, and $x_{\text {max }}$ denotes the maximum particle size. $x_{i}$ is the particle size distribution of each size range.

\section{Numerical Results and Discussion}

In this section, a trajectory model of the mantle is established by an eccentric simulation. The main purpose is to solve the input velocities and driving forces of a 6-DOF robotic crusher. At the same time, it demonstrates the suggested approach can solve the dynamic problem effectively. Furthermore, the power of six actuators and energy consumption are calculated.

4.1. Example. The parameters of a 6-DOF robotic crusher are presented in Table 1 . The trajectory model of the mantle is an essential element for establishing the kinematic and dynamic equations for the 6-DOF robotic crusher. But it is very difficult to be established by using analytical method.

A small-scale cone crusher is created in a virtual environment by using ADAMS in order to obtain the trajectory 
TABLE 2: Position and orientation of point $\mathrm{O}_{1}$ relative to the fixed point $\mathrm{O}_{1 \mathrm{G}}$.

\begin{tabular}{lccccrc}
\hline Time & AX & AY & AZ & DX & DY & DZ \\
\hline $0.0000 \mathrm{E}+00$ & $-3.6704 \mathrm{E}-16$ & $-2.2204 \mathrm{E}-16$ & $-1.0644 \mathrm{E}-16$ & $3.5527 \mathrm{E}-15$ & $-5.6843 \mathrm{E}-14$ & $0.0000 \mathrm{E}+00$ \\
$1.0000 \mathrm{E}-02$ & $5.6775 \mathrm{E}-04$ & $1.3695 \mathrm{E}-04$ & $-1.3246 \mathrm{E}-03$ & $1.4558 \mathrm{E}-03$ & $-2.5174 \mathrm{E}-01$ & $0.0000 \mathrm{E}+00$ \\
$2.0000 \mathrm{E}-02$ & $1.0441 \mathrm{E}-03$ & $3.1864 \mathrm{E}-04$ & $-2.3878 \mathrm{E}-03$ & $-3.0296 \mathrm{E}-03$ & $-4.5261 \mathrm{E}-01$ & $0.0000 \mathrm{E}+00$ \\
$3.0000 \mathrm{E}-02$ & $1.5862 \mathrm{E}-03$ & $2.8426 \mathrm{E}-04$ & $-3.5293 \mathrm{E}-03$ & $-2.6240 \mathrm{E}-02$ & $-6.6657 \mathrm{E}-01$ & $0.0000 \mathrm{E}+00$ \\
$3.7012 \mathrm{E}-02$ & $2.0335 \mathrm{E}-03$ & $1.9493 \mathrm{E}-04$ & $-4.3315 \mathrm{E}-03$ & $-2.8522 \mathrm{E}-02$ & $-8.1314 \mathrm{E}-01$ & $0.0000 \mathrm{E}+00$ \\
$\vdots$ & $\vdots$ & $\vdots$ & $\vdots$ & $\vdots$ & $\vdots$ \\
$1.9980 \mathrm{E}+01$ & $-3.9468 \mathrm{E}-02$ & $-5.2918 \mathrm{E}-02$ & $7.5980 \mathrm{E}-02$ & $-1.7257 \mathrm{E}+01$ & $1.4016 \mathrm{E}+01$ & $0.0000 \mathrm{E}+00$ \\
$1.9987 \mathrm{E}+01$ & $-3.9775 \mathrm{E}-02$ & $-5.2547 \mathrm{E}-02$ & $7.6331 \mathrm{E}-02$ & $-1.7122 \mathrm{E}+01$ & $1.4074 \mathrm{E}+01$ & $0.0000 \mathrm{E}+00$ \\
$1.9990 \mathrm{E}+01$ & $-3.9957 \mathrm{E}-02$ & $-5.2380 \mathrm{E}-02$ & $7.6586 \mathrm{E}-02$ & $-1.7053 \mathrm{E}+01$ & $1.4118 \mathrm{E}+01$ & $0.0000 \mathrm{E}+00$ \\
$1.9996 \mathrm{E}+01$ & $-4.0095 \mathrm{E}-02$ & $-5.2092 \mathrm{E}-02$ & $7.6557 \mathrm{E}-02$ & $-1.6902 \mathrm{E}+01$ & $1.4104 \mathrm{E}+01$ & $0.0000 \mathrm{E}+00$ \\
$2.0000 \mathrm{E}+01$ & $-4.0052 \mathrm{E}-02$ & $-5.1936 \mathrm{E}-02$ & $7.6583 \mathrm{E}-02$ & $-1.6836 \mathrm{E}+01$ & $1.4112 \mathrm{E}+01$ & $0.0000 \mathrm{E}+00$ \\
\hline
\end{tabular}

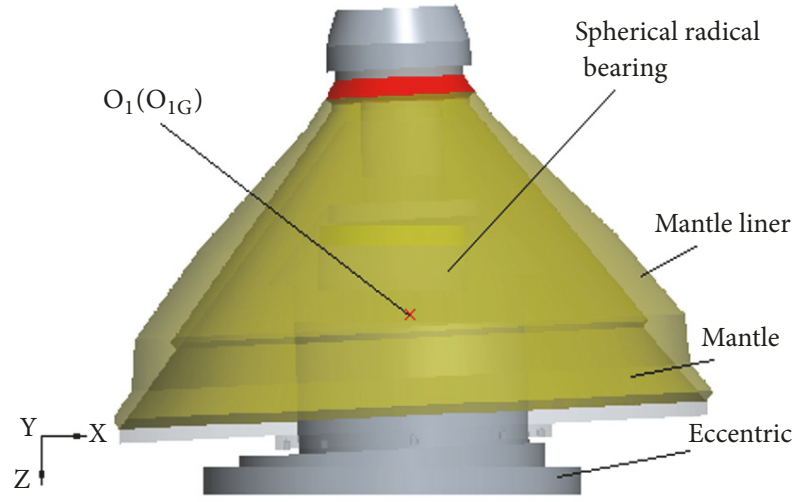

FIGURE 7: The model of a small-scale cone crusher.

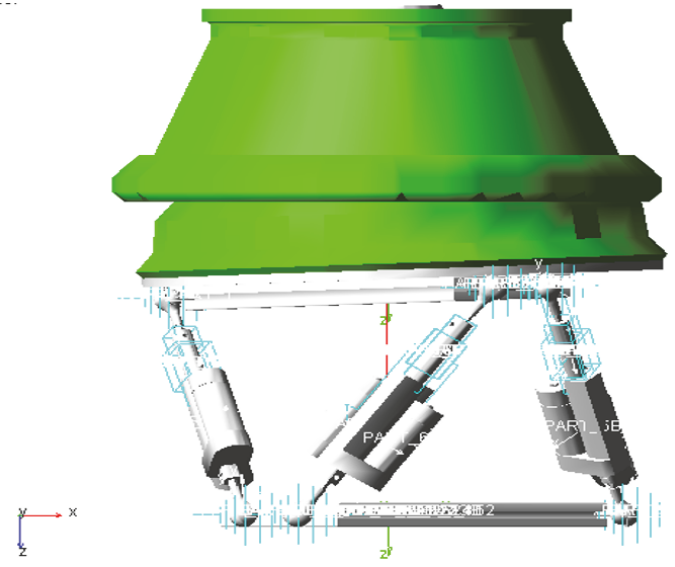

Figure 8: The dynamic model in ADAMS. model of the mantle, which can be shown in Figure 7. The oscillating motion of the mantle is accomplished by the eccentric simulation. Position and orientation of point $\mathrm{O}_{1}$ relative to the fixed point $\mathrm{O}_{1 \mathrm{G}}$ can be extracted and shown in Table 2.

The movement simulation based on ADAMS is carried out to establish the trajectory model of the mantle for the 6DOF robotic crusher. Then, the model of the mantle frame $\left\{\mathrm{O}_{1}, \mathrm{X}_{1}, \mathrm{Y}_{1}, \mathrm{Z}_{1}\right\}$ relative to the reference frame $\{\mathrm{O}, \mathrm{X}, \mathrm{Y}, \mathrm{Z}\}$ can be described as

$$
\begin{aligned}
& \mathbf{q}_{\mathbf{e}}=\left[\begin{array}{c}
0.044 \sin (\omega t) \\
0.044 \cos (\omega t) \\
-0.078 \sin (\omega t)
\end{array}\right] \mathrm{rad} \\
& \mathbf{q}_{\mathbf{p}}=\left[\begin{array}{c}
14.36 \cos (\omega t)-4.864 \\
-14.36 \sin (\omega t) \\
0
\end{array}\right] \mathrm{mm}
\end{aligned}
$$

where $\omega=1.483 \mathrm{rad} / \mathrm{s}$.

The proposed approach is used to solve the kinematic and dynamic equations. Input velocities and driving forces of six actuators have the same time period, as shown in Figures 9 and 10. Input velocities of actuators 4 and 5 are greater than others. Negative value indicates that the actuator is contracting. The values of driving forces are in the interval $[240,460]$, and the maximum value is found on actuators 3 and 6. They can be used as a basis for the design and component selection. The difference of the peak value is related to the eccentric angle and selection of the initial position.

4.2. Simulation Verification. Settings of connectors and motions of 3D model in ADAMS are shown in Figure 8 [22]. In order to validate the proposed approach, driving forces of six actuators are simulated by using ADAMS, which are represented in Figure 11. Figures 10 and 11 are obtained by executing the simulation for 20s. It can be observed that the calculated and simulated outputs have good agreements, which indicates the suggested approach of dynamic modeling is suitably selected.

Compared with the driving forces, the friction of spherical joints and actuators is negligible. Therefore, power of six actuators can be expressed as follows according to (13) and (17):

$$
P_{\text {out }}=\boldsymbol{\tau}^{\mathrm{T}} \cdot \dot{\mathbf{q}}
$$




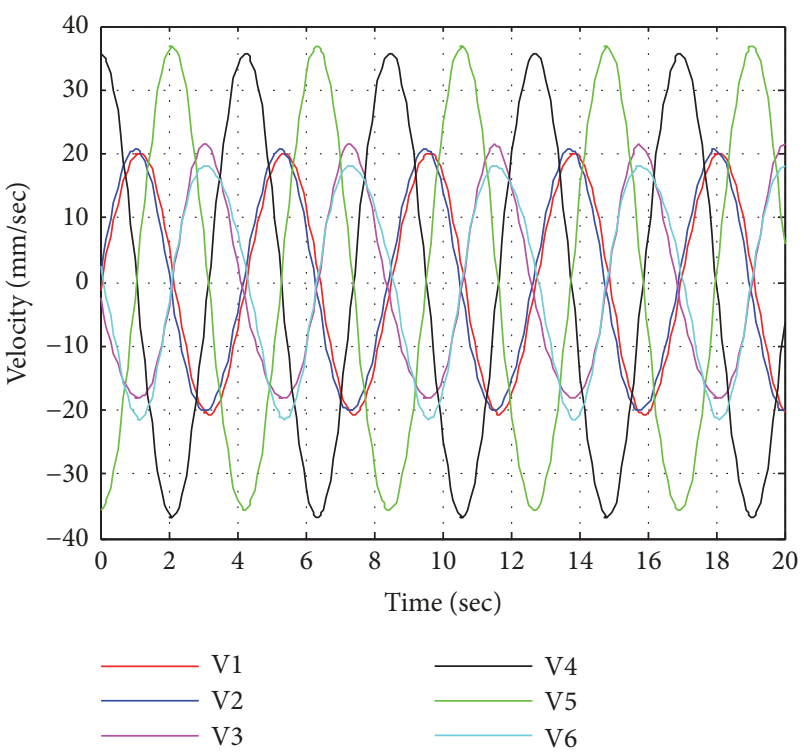

FIgURE 9: Input velocities of six actuators.

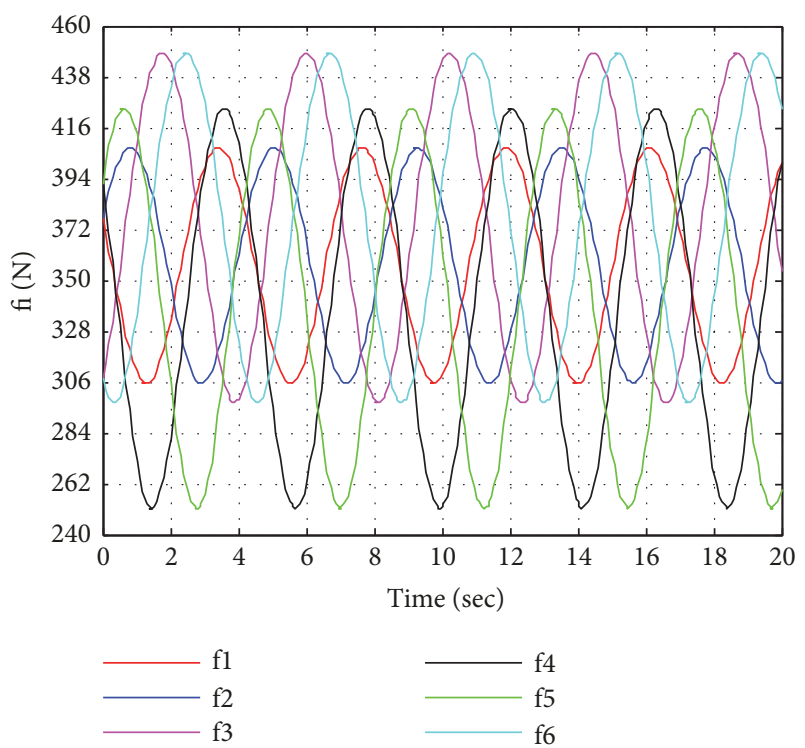

FIgURE 10: Driving forces of six actuators.

The derivation of (52) is in the appendix.

Power of six actuators can be described with a cyclic function of the time, as shown in Figure 12. Power is only related to the payload consumption when six actuators are all expanding, and it has nothing to do with the structure. The energy consumption of the 6-DOF robotic crusher can be mainly divided into two parts: energy consumption during breakage $E_{1}$ and no-load mechanical energy $E_{0}$. $E_{1}$ is obtained by integrating the pressure $p$ over the stroke $s$ and multiplying the cross-sectional surface area $A$ perpendicular to the compressed volume. Similarly, $E_{0}$ can be calculated by integrating the power of six actuators over the time.
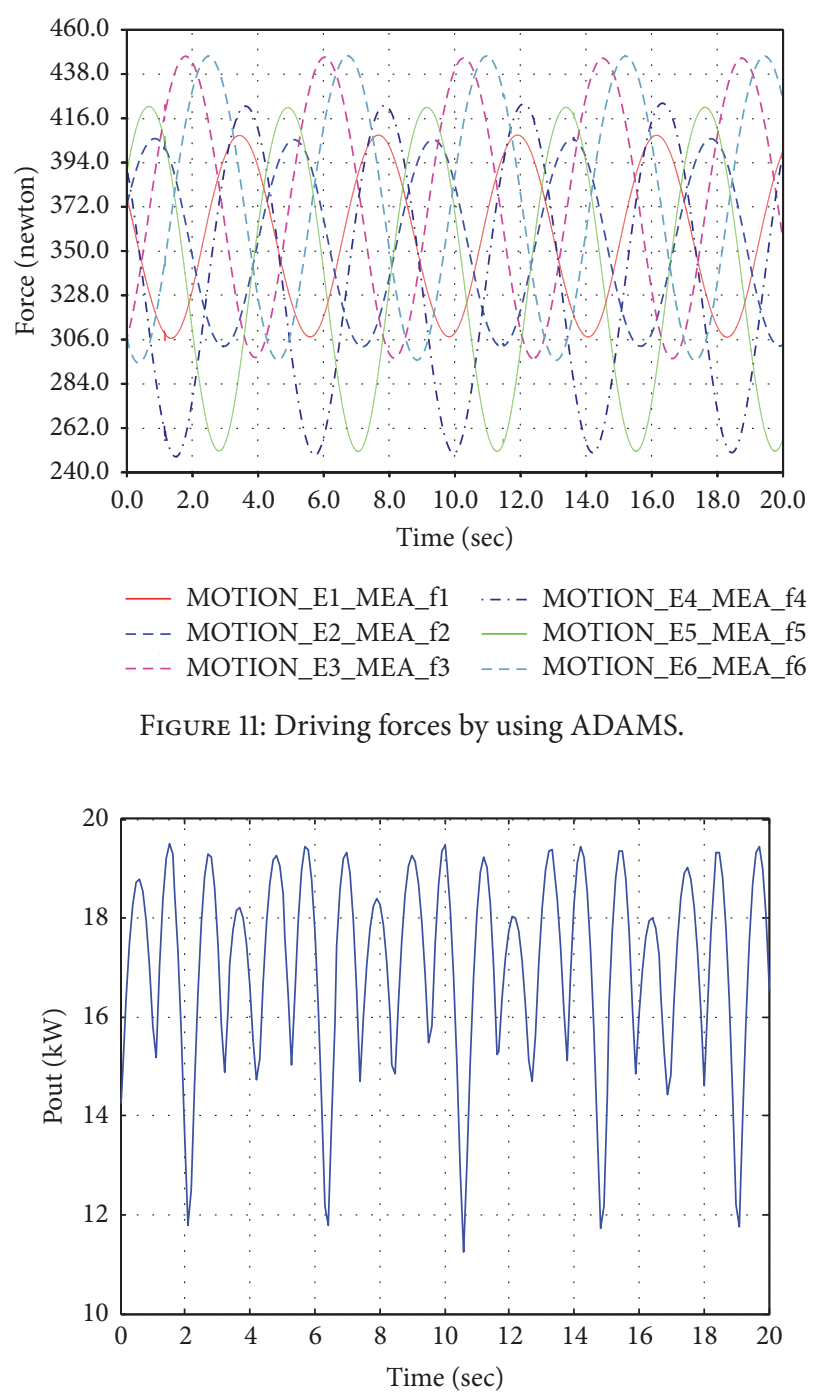

Figure 12: Power of six actuators.

Therefore, the energy consumption $E$ of the 6-DOF robotic crusher can be expressed as

$$
E=E_{1}+E_{0}=\int_{0}^{S_{\text {act }}} \int_{0}^{A_{\text {act }}} p(\varepsilon, \sigma) d A d s+\int_{0}^{T} P_{\text {out }} d t
$$

where $T$ represents the crushing period of particles.

\section{Conclusions}

A novel 6-DOF robotic crusher was proposed which could achieve both interparticle breakage of a cone crusher and high flexibility of a parallel robot. The kinematic and dynamic models were derived from the no-load and crushing parts in order to systematically describe the performance characteristics. For the no-load case, the kinematic model was established by analytical geometry and Jacobian matrix was conducted. The dynamic model which takes into account the weight of the mantle and actuators was derived based on the Lagrange equation. For the crushing case, the crushing process could be described by a number of different crushing 
zones. The crushing pressure was related to the compression ratio and particle size distribution, and the closed side was the largest location of the same horizontal cross section. In order to establish the trajectory model of the mantle, a smallscale cone crusher was created and the model was obtained by an eccentric simulation. The result showed that the position and orientation functions changed periodically. Then the mathematical calculation tools, MATLAB and Maple, were employed to solve the input velocities and driving forces of actuators. The suggested approach had been verified by using ADAMS. Input velocity and driving force of each actuator were different due to the eccentric angle and selection of the initial position. Finally, the power of six actuators and energy consumption were given.

\section{Appendix}

Differentiating $\mathbf{T}_{\mathrm{X}}, \mathbf{T}_{\mathrm{Y}}$, and $\mathbf{T}_{\mathrm{Z}}$ with respect to time, (4) can be derived as

$$
\begin{aligned}
\dot{\mathbf{T}}_{\mathrm{X}} & =\left[\begin{array}{ccc}
0 & 0 & 0 \\
0 & -\sin \alpha & -\cos \alpha \\
0 & \cos \alpha & -\sin \alpha
\end{array}\right] \dot{\alpha}=\mathbf{S}_{\mathbf{i}} \mathbf{T}_{\mathbf{X}} \dot{\alpha}, \\
\dot{\mathbf{T}}_{\mathrm{Y}} & =\left[\begin{array}{ccc}
-\sin \beta & 0 & \cos \beta \\
0 & 0 & 0 \\
-\cos \beta & 0 & -\sin \beta
\end{array}\right] \dot{\beta}=\mathbf{S}_{\mathbf{j}} \mathbf{T}_{Y} \dot{\beta} \\
\dot{\mathbf{T}}_{\mathrm{Z}} & =\left[\begin{array}{ccc}
-\sin \gamma & -\cos \gamma & 0 \\
\cos \gamma & -\sin \gamma & 0 \\
0 & 0 & 0
\end{array}\right] \dot{\gamma}=\mathbf{S}_{\mathbf{k}} \mathbf{T}_{\mathbf{Z}} \dot{\gamma}
\end{aligned}
$$

For any length of an actuator, it can be obtained as

$$
l_{i}^{2}=\mathbf{l}_{i}^{\mathrm{T}} \cdot \mathbf{l}_{i}
$$

Therefore, the following equation can be deduced as

$$
\mathbf{Q}_{i}=\frac{\mathbf{L}_{i}^{\mathrm{T}}}{L_{i}}
$$

where $\mathbf{Q}_{\mathbf{i}}$ is the unit vector of each actuator.

Using (A.2) and (A.3), (6) can be derived as

$$
\begin{aligned}
& {\left[\begin{array}{llllll}
\dot{L}_{1} & \dot{L}_{2} & \dot{L}_{3} & \dot{L}_{4} & \dot{L}_{5} & \dot{L}_{6}
\end{array}\right]^{\mathrm{T}}} \\
& \quad=\mathbf{Q} \cdot\left[\begin{array}{llllll}
\dot{\mathbf{L}}_{1} & \dot{\mathbf{L}}_{2} & \dot{\mathbf{L}}_{3} & \dot{\mathbf{L}}_{4} & \dot{\mathbf{L}}_{5} & \dot{\mathbf{L}}_{6}
\end{array}\right]^{\mathrm{T}}
\end{aligned}
$$

where

$$
\mathbf{Q}=\operatorname{diag}\left\{\mathbf{Q}_{1}, \mathbf{Q}_{2}, \mathbf{Q}_{3}, \mathbf{Q}_{4}, \mathbf{Q}_{5}, \mathbf{Q}_{6}\right\}
$$

The ratio between $g_{i}$ and $l_{i}$ is defined as

$$
h_{g i}=\frac{g_{i}}{l_{i}}=\frac{l_{c}}{l_{i}}+\frac{m_{2}}{m_{1}+m_{2}}
$$

Using (A.6), the velocity vectors for the center of mass can be given by

$$
\mathbf{V}_{\mathrm{gi}}=h_{g i} \cdot \dot{\mathbf{L}}_{i}
$$

Then, (26) can be obtained as follows:

$$
\mathbf{V}_{g}=\left[\mathbf{V}_{\mathrm{g} 1}^{\mathrm{T}}, \mathbf{V}_{\mathrm{g} 2}^{\mathrm{T}}, \mathbf{V}_{\mathrm{g} 3}^{\mathrm{T}}, \mathbf{V}_{\mathrm{g} 4}^{\mathrm{T}}, \mathbf{V}_{\mathrm{g} 5}^{\mathrm{T}}, \mathbf{V}_{\mathrm{g} 6}^{\mathrm{T}}\right]^{\mathrm{T}}
$$

Using (20) and (27), (33) can be derived as

$$
\begin{aligned}
E_{k} & =\frac{1}{2} \dot{\mathbf{q}}^{\mathrm{T}} \mathbf{M}_{\mathrm{p}} \dot{\mathbf{q}}+\frac{1}{2}\left(m_{1}+m_{2}\right) \dot{\mathbf{q}}^{\mathrm{T}} \mathbf{H}^{\mathrm{T}} \mathbf{T}_{\mathrm{m}} \mathbf{H} \dot{\mathbf{q}} \\
& =\frac{1}{2} \dot{\mathbf{q}}^{\mathrm{T}}\left[\left(m_{1}+m_{2}\right) \mathbf{H}^{\mathrm{T}} \mathbf{T}_{\mathrm{m}} \mathbf{H}+\mathbf{M}_{\mathrm{p}}\right] \dot{\mathbf{q}} \\
& =\frac{1}{2} \dot{\mathbf{q}}^{\mathrm{T}} \mathbf{M}_{\mathrm{ek}} \dot{\mathbf{q}}
\end{aligned}
$$

Equation (36) can be deduced as

$$
\frac{\mathrm{d}}{\mathrm{d} t}\left(\frac{\partial L}{\partial \dot{\mathbf{q}}}\right)=\frac{\mathrm{d}}{\mathrm{d} t}\left(\mathbf{M}_{\mathrm{ek}} \dot{\mathbf{q}}\right)=\dot{\mathbf{M}}_{\mathrm{ek}} \dot{\mathbf{q}}+\mathbf{M}_{\mathrm{ek}} \ddot{\mathbf{q}}
$$

where (15) and (33) have been employed.

Equation (37) can be further derived as

$$
\frac{\partial E_{k}}{\partial \mathbf{q}}=\frac{1}{2} \dot{\mathbf{q}}^{\mathrm{T}}\left(\frac{\partial \mathbf{M}_{\mathrm{ek}}}{\partial \mathbf{q}}\right) \dot{\mathbf{q}}
$$

where

$$
\begin{aligned}
& \mathbf{M}_{\mathrm{ek}}=\left(m_{1}+m_{2}\right) \mathbf{H}^{\mathrm{T}} \mathbf{T}_{\mathrm{m}} \mathbf{H}+\mathbf{M}_{\mathrm{p}}, \\
& \frac{\partial \mathbf{M}_{\mathrm{ek}}}{\partial X}=\left(m_{1}+m_{2}\right) \mathbf{H}^{\mathrm{T}} \frac{\partial \mathbf{T}_{\mathrm{m}}}{\partial X} \mathbf{H}, \\
& \frac{\partial \mathbf{M}_{\mathrm{ek}}}{\partial Y}=\left(m_{1}+m_{2}\right) \mathbf{H}^{\mathrm{T}} \frac{\partial \mathbf{T}_{\mathrm{m}}}{\partial Y} \mathbf{H}, \\
& \frac{\partial \mathbf{M}_{\mathrm{ek}}}{\partial Z}=\left(m_{1}+m_{2}\right) \mathbf{H}^{\mathrm{T}} \frac{\partial \mathbf{T}_{\mathrm{m}}}{\partial Z} \mathbf{H}, \\
& \frac{\partial \mathbf{M}_{\mathrm{ek}}}{\partial \alpha}=\left(m_{1}+m_{2}\right)
\end{aligned}
$$$$
\cdot\left[\frac{\partial \mathbf{H}^{\mathrm{T}}}{\partial \alpha} \mathbf{T}_{\mathrm{m}} \mathbf{H}+\mathbf{H}^{\mathrm{T}} \frac{\partial \mathbf{T}_{\mathrm{m}}}{\partial \alpha} \mathbf{H}+\mathbf{H}^{\mathrm{T}} \mathbf{T}_{\mathrm{m}} \frac{\partial \mathbf{H}}{\partial \alpha}\right]
$$$$
+\frac{\partial \mathbf{M}_{\mathrm{p}}}{\partial \alpha}
$$

$$
\frac{\partial \mathbf{M}_{\mathrm{ek}}}{\partial \beta}=\left(m_{1}+m_{2}\right)
$$$$
\cdot\left[\frac{\partial \mathbf{H}^{\mathrm{T}}}{\partial \beta} \mathbf{T}_{\mathrm{m}} \mathbf{H}+\mathbf{H}^{\mathrm{T}} \frac{\partial \mathbf{T}_{\mathrm{m}}}{\partial \beta} \mathbf{H}+\mathbf{H}^{\mathrm{T}} \mathbf{T}_{\mathrm{m}} \frac{\partial \mathbf{H}}{\partial \beta}\right]
$$

$$
+\frac{\partial \mathbf{M}_{\mathrm{p}}}{\partial \beta}
$$$$
\frac{\partial \mathbf{M}_{\mathrm{ek}}}{\partial \gamma}=\left(m_{1}+m_{2}\right)
$$

$$
\cdot\left[\frac{\partial \mathbf{H}^{\mathrm{T}}}{\partial \gamma} \mathbf{T}_{\mathrm{m}} \mathbf{H}+\mathbf{H}^{\mathrm{T}} \frac{\partial \mathbf{T}_{\mathrm{m}}}{\partial \gamma} \mathbf{H}+\mathbf{H}^{\mathrm{T}} \mathbf{T}_{\mathrm{m}} \frac{\partial \mathbf{H}}{\partial \gamma}\right]
$$


Equation (52) can be deduced as

$$
P_{\text {out }}=\boldsymbol{\tau}^{\mathrm{T}} \cdot \mathbf{J}_{\mathrm{q}}^{-1} \cdot \mathbf{J}_{\mathrm{q}} \cdot \dot{\mathbf{q}}=\boldsymbol{\tau}^{\mathrm{T}} \cdot \dot{\mathbf{q}}
$$

\section{Data Availability}

There were no data used to support this study.

\section{Conflicts of Interest}

The authors declare that there are no conflicts of interest regarding the publication of this paper.

\section{Acknowledgments}

This work was supported by the National Key Research and Development Program of China (no. 2016YFC0600805).

\section{References}

[1] H. Li, G. McDowell, and I. Lowndes, "A laboratory investigation and discrete element modeling of rock flow in a chute," Powder Technology, vol. 229, pp. 199-205, 2012.

[2] P. W. Cleary and M. D. Sinnott, "Simulation of particle flows and breakage in crushers using DEM: Part 1 - Compression crushers," Minerals Engineering, vol. 74, pp. 178-197, 2015.

[3] Z. Zhang, T. Ren, J. Cheng, and X. Jin, “The improved model of inter-particle breakage considering the transformation of particle shape for cone crusher," Minerals Engineering, vol. 112, pp. 11-18, 2017.

[4] G. W. Delaney, R. D. Morrison, M. D. Sinnott, S. Cummins, and P. W. Cleary, "DEM modelling of non-spherical particle breakage and flow in an industrial scale cone crusher," Minerals Engineering, vol. 74, pp. 112-122, 2015.

[5] R. Liu, B. Shi, G. Li, and H. Yu, "Influence of operating conditions and crushing chamber on energy consumption of cone crusher," Energies, vol. 11, no. 5, 2018.

[6] M. Lindqvist and C. Evertsson, "Improved flow- and pressure model for cone crushers," Minerals Engineering, vol. 17, no. 1112, pp. 1217-1225, 2004.

[7] X. Huang, Q. Liao, and S. Wei, "Closed-form forward kinematics for a symmetrical 6-6 Stewart platform using algebraic elimination," Mechanism and Machine Theory, vol. 45, no. 2, pp. 327-334, 2010.

[8] S. Staicu, "Dynamics of the 6-6 Stewart parallel manipulator," Robotics and Computer-Integrated Manufacturing, vol. 27, no. 1, pp. 212-220, 2011.

[9] V. Damic and M. Cohodar, "Dynamic analysis of stewart platform by bond graphs," Procedia Engineering, vol. 100, pp. 226-233, 2015.

[10] I. Miletović, D. Pool, O. Stroosma, M. van Paassen, and Q. Chu, "Improved Stewart platform state estimation using inertial and actuator position measurements," Control Engineering Practice, vol. 62, pp. 102-115, 2017.

[11] M. A. Mirza, S. Li, and L. Jin, "Simultaneous learning and control of parallel Stewart platforms with unknown parameters," Neurocomputing, vol. 266, pp. 114-122, 2017.

[12] H. Jiang, J. He, Z. Tong, and W. Wang, "Dynamic isotropic design for modified Gough-Stewart platforms lying on a pair of circular hyperboloids," Mechanism and Machine Theory, vol. 46, no. 9, pp. 1301-1315, 2011.
[13] H. Jiang, Z. Tong, and J. He, "Dynamic isotropic design of a class of Gough-Stewart parallel manipulators lying on a circular hyperboloid of one sheet," Mechanism and Machine Theory, vol. 46, no. 3, pp. 358-374, 2011.

[14] A. M. Lopes, "Dynamic modeling of a Stewart platform using the generalized momentum approach," Communications in Nonlinear Science and Numerical Simulation, vol. 14, no. 8, pp. 3389-3401, 2009.

[15] P. Mukherjee, B. Dasgupta, and A. Mallik, "Dynamic stability index and vibration analysis of a flexible Stewart platform," Journal of Sound and Vibration, vol. 307, no. 3-5, pp. 495-512, 2007.

[16] M. M. Horoub, M. Hassan, and M. A. Hawwa, "Workspace analysis of a Gough-Stewart type cable marine platform subjected to harmonic water waves," Mechanism and Machine Theory, vol. 120, pp. 314-325, 2018.

[17] Y. Tu, G. Yang, Q. Cai, L. Wang, and X. Zhou, "Optimal design of SINS's Stewart platform bumper for restoration accuracy based on genetic algorithm," Mechanism and Machine Theory, vol. 124, pp. 42-54, 2018.

[18] G. Liu, Z. Qu, X. Liu, and J. Han, “Tracking performance improvements of an electrohydraulic Gough-Stewart platform using a fuzzy incremental controller," Industrial Robot: An International Journal, vol. 41, no. 2, pp. 225-235, 2014.

[19] H. B. Guo and H. R. Li, "Dynamic analysis and simulation of a six degree of freedom Stewart platform manipulator," Proceedings of the Institution of Mechanical Engineers, Part C: Journal of Mechanical Engineering Science, vol. 220, no. 1, pp. 61-72, 2006.

[20] Z.-Y. Jia, S. Lin, and W. Liu, "Measurement method of six-axis load sharing based on the Stewart platform," Measurement, vol. 43, no. 3, pp. 329-335, 2010.

[21] R. Liu, B. Shi, Y. Shen, and G. Li, "Prediction model for liner wear considering the motion characteristics of material," Mathematical Problems in Engineering, vol. 2018, 2018.

[22] Y. Wu, K. Yu, J. Jiao, D. Cao, W. Chi, and J. Tang, "Dynamic isotropy design and analysis of a six-DOF active microvibration isolation manipulator on satellites," Robotics and Computer-Integrated Manufacturing, vol. 49, pp. 408-425, 2018. 


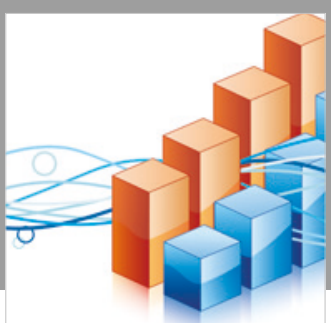

Advances in

Operations Research

\section{-n-m}
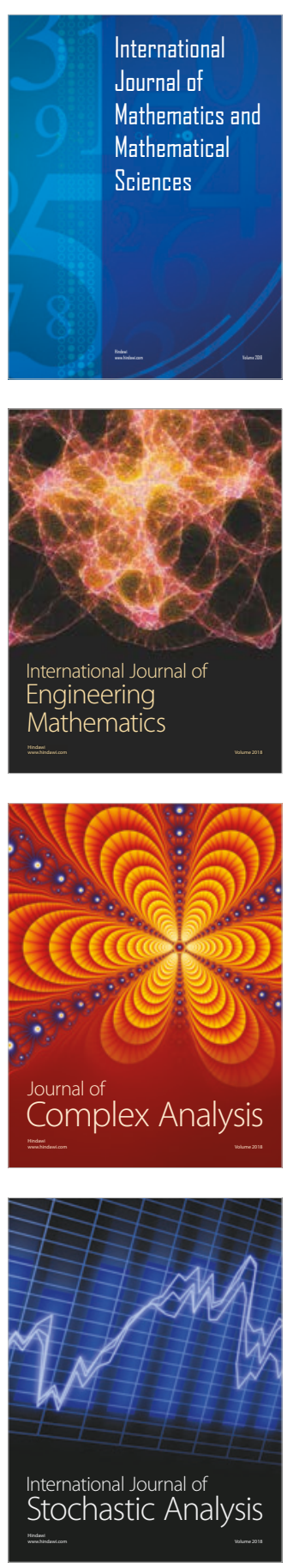
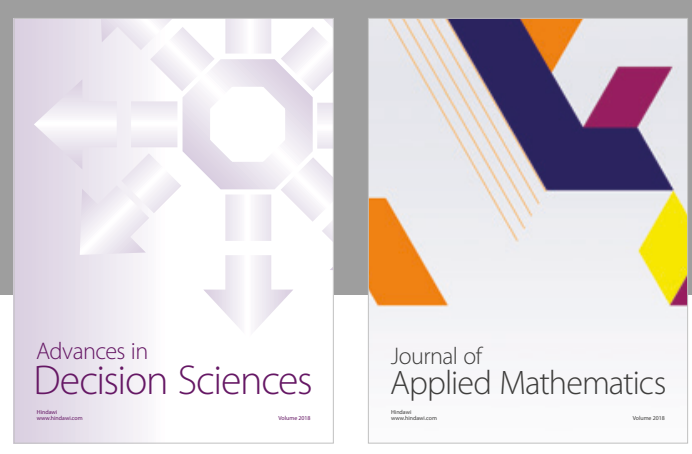

Journal of

Applied Mathematics
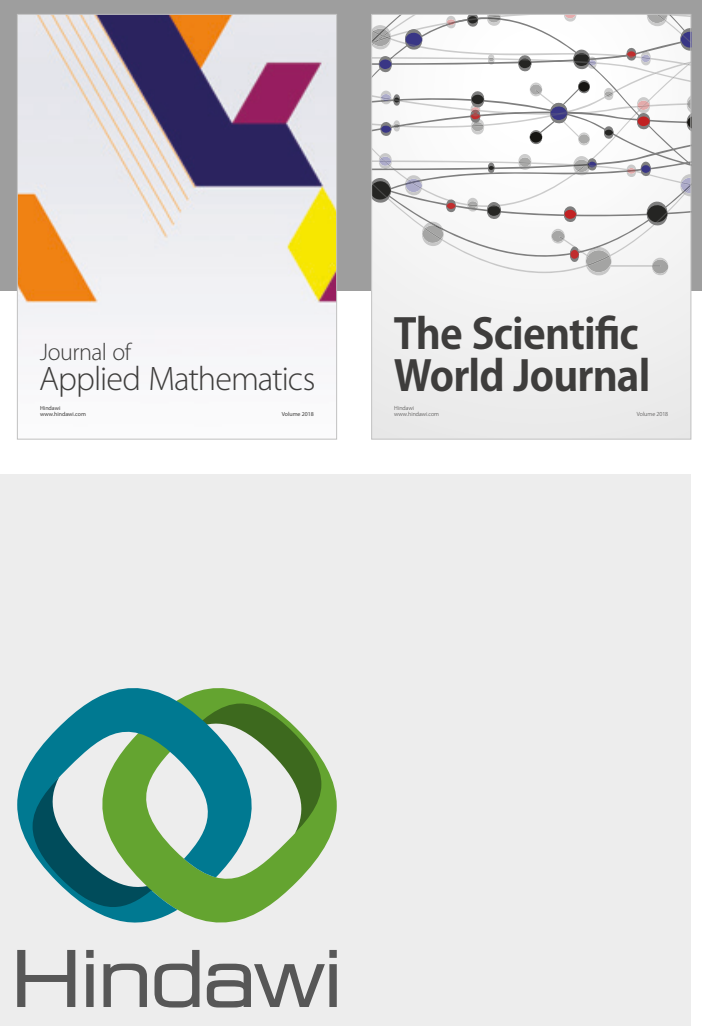

Submit your manuscripts at

www.hindawi.com

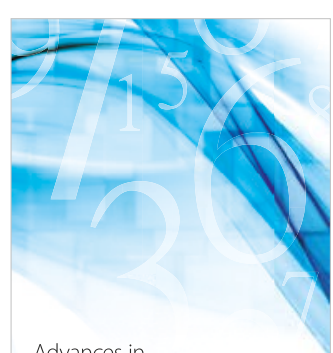

Advances in
Numerical Analysis
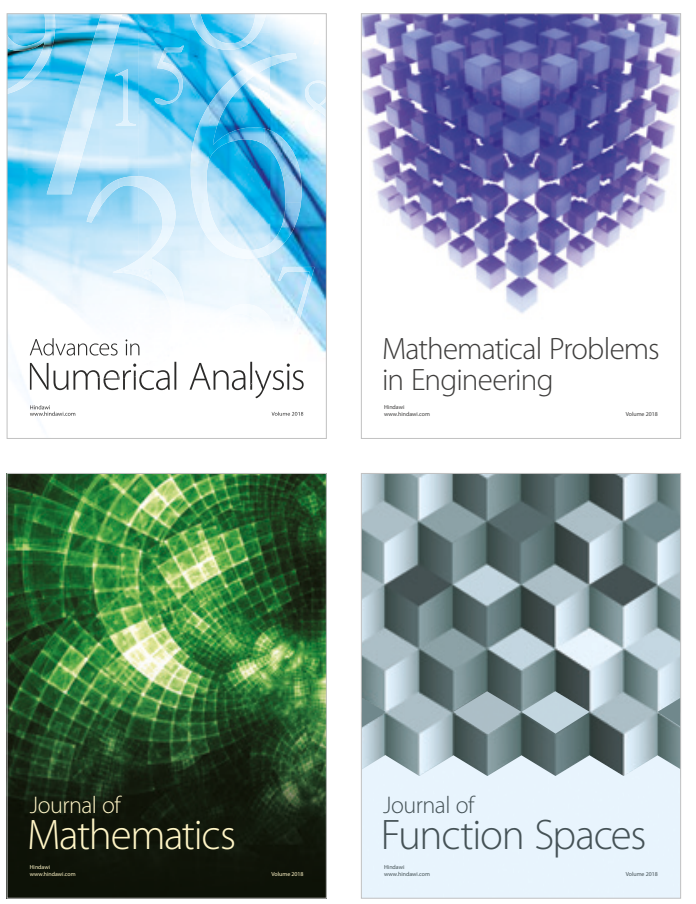

Mathematical Problems in Engineering

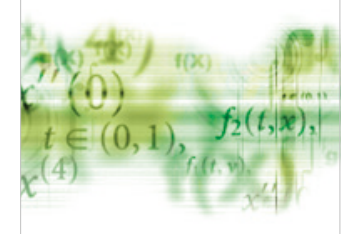

International Journal of

Differential Equations

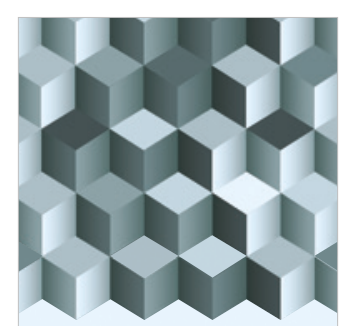

Journal of

Function Spaces

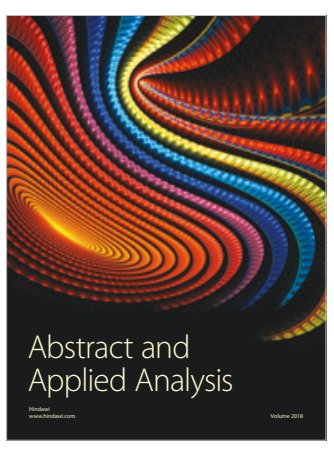

The Scientific

World Journal

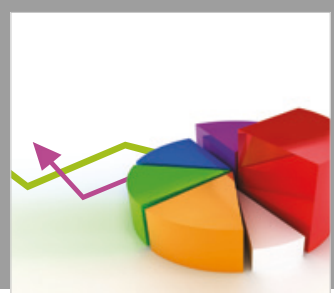

Journal of

Probability and Statistics
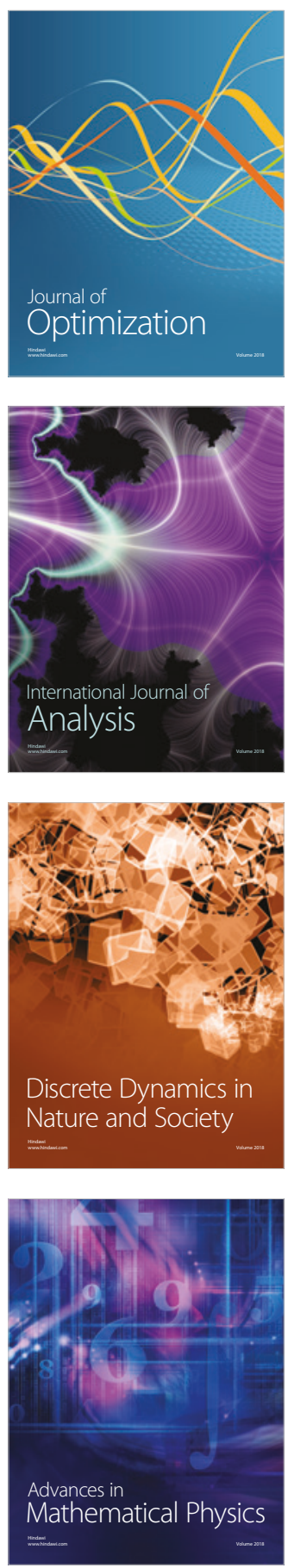